\title{
Analysis of the bearing capacity of continuous flight auger piles in terms of their excavation energy and of rainfall data
}

\author{
Darym J. Ferrari de Campos ${ }^{1, *}$, José Camapum de Carvalho ${ }^{1}$, Gilson F. N. Gitirana Jr. ${ }^{2}$, Andre L. B. Cavalcante ${ }^{1}$, and Luan \\ C. S. M. Ozelim ${ }^{1}$
}

${ }^{1}$ Department of Civil and Environmental Engineering, University of Brasília, Brasília-DF, Brazil

${ }^{2}$ School of Civil and Environmental Engineering, Federal University of Goiás, Goiania-GO, Brazil

\begin{abstract}
Continuous flight auger piles (CFAs) are among the most common types of foundation executed in the tropical residual soil of Brasília, DF, Brazil. The bearing capacity of CFAs can be controlled according to the energy required to excavate each pile but is also influenced by seasonal conditions that affect the unsaturated soil profile. In the present article, a database of controlled execution of CFAs carried out at Brasília-DF was evaluated. The execution methodology enabled the full control of the drilling energy. Load tests were also performed and the pile bearing capacity was estimated by extrapolating the load-settlement curve using the van Der Veen method. As the site was excavated before the foundation was built, the morphology of the site was also considered in the analyses. Furthermore, by comparing the execution energies and climatological information, a relation between the moisture indexes and the execution energies was investigated. From these analyses, discussions regarding the relation between the bearing capacity of the piles tested and the rainfall regime they have been subjected to are presented. The changes observed in bearing capacity due to climatological effects may lead to economical savings and offer enhanced reliability in the design of CFAs.
\end{abstract}

\section{Introduction}

Tropical soils, normally found in humid regions, present peculiar properties and behaviour due to the action of specific geological and pedological processes. In general, these soils can be classified as saprolitic or lateritic soils. The soil of Brasilia-DF is classified as a tropical laterite, composed by a porous red collapsible clay, which consists of clays, silts and sands combined in different proportions depending on the local geology. The clay layers can be over 10 meters deep and due to their high porosity and cementation bonds; they present unstable structures when subjected to wetting and loading paths. In this local scenario, it is common to find the water level at greater depths. Classically, we consider saturated theory to model the soil behaviour during foundation designs, but in many situations, especially in countries with tropical climate, it is necessary to emphasize studies and analyses considering the unsaturated state of soils. It is known that the saturated and unsaturated states of the soil influence its behaviour, specially the bearing capacity of foundations built upon it. Soil characterization and bearing capacity studies are essential to increase the safety and efficiency of foundation designs.

In short, the lateritic soils are characterized by a deeply weathered profile, and are normally found in the unsaturated state near the surface.

When dealing with the execution of any kind of foundation above the water table, the morphology of the construction site, as well as the existing climatic conditions, will affect the movement of water within the porous matrix and consequently the behaviour of the soil. It is important to realize that, as Reinert (2011) [1] indicates, geotechnical uncertainties are present in any geotechnical investigation, mainly because of the natural variability of geological formations. That author also indicates that, considering that the weathering processes produce transformations in the profile, it is often difficult to precisely define the stratigraphy of the terrain as well as to predict the complete composition of the constituents of the soil matrix. Therefore, testing and understanding the factors which will impact the mechanical behaviour of the soil is important. This is where the unsaturated behaviour comes into play.

In order to better understand the behaviour of continuous flight auger piles (CFAs) frequently built above the water table and mitigate geotechnical uncertainties, Silva (2011) [2] studied an execution control technique based on an automated measurement of the work performed (or the energy required) to execute each pile. It is worth noticing that this type of equipment is commonly used in Brazil.

By considering this control technique, the executor and the designer can verify the mechanical work performed during the execution of each element of the foundation. Results from that author indicate that there is a relation between execution energy and the bearing capacity of piles, thus, controlling the energy/work allows

* Corresponding author: darymjunior@gmail.com 
a detailed control along the depth of each region of the construction site.

Considering that both the unsaturated state and the execution energies are related to the bearing capacity of CFAs, the objective of this present paper is to analyse how unsaturated soil strata impact the execution energy of CFAs. In this context, to characterize distinct execution scenarios, pluviometry data is used to indirectly represent the amount of water present in the shallower strata of the soil profile.

\section{Characteristics of the piles and stratigraphic profile}

The stratigraphic profile chosen for this article corresponds to a foundation structure located in BrasíliaDF, Brazil. The complete characterization of the geotechnical infrastructure of the construction can be found in Ferrari de Campos (2018) [3].

The first stage of construction consisted in executing a retaining diaphragm wall. After its implementation, the lot was excavated for a total of 9.2 meters in depth. Then, the foundation piles were executed. Before the execution of the foundation piles, four Standard Penetration Tests (SPT) and soil surveys were performed.

The results of the soil surveys were interpolated throughout the construction site using the RockWorks software. For the interpolation, the Inverse-Distance Anisotropic weighted distance method was used. For this article, six piles with similar geometric and stratigraphic characteristics were chosen. The characteristics of the CFAs are observed on Table 1. On the other hand, the field spatialization (longitudinal section $\mathrm{A}-\mathrm{A}^{\prime}$ ) and the location of each of the studied piles can be seen in Fig. 1.

The date of execution (day-month-year) becomes an important information. Three piles executed during the rainy season and three additional piles were executed during the dry season. In order to characterize the periods, the precipitation events in an interval of 10 days prior to the effective execution of each pile were considered. The adopted antecedent precipitation window depends largely on the seepage regime, hydraulic conductivity, and analysed depths. Soils with higher permeability and problems with smaller dimensions require the consideration of shorter precipitation windows. Therefore, the time window can be changed to better represent the impact of rainy days on the soil profile water content, but this is out of the scope of the present paper and shall be treated in subsequent studies.

Table 1. Characteristics of the analysed piles.

\begin{tabular}{c|c|c|c|c}
\hline Pile & $\begin{array}{c}\text { Diameter } \\
(\mathbf{m})\end{array}$ & $\begin{array}{c}\text { Length } \\
(\mathbf{m})\end{array}$ & $\begin{array}{c}\text { Execution } \\
\text { Date }\end{array}$ & Season \\
\hline P10BB & 0.5 & 14 & $08 / 03 / 2016$ & Rainy \\
P8BC & 0.5 & 14 & $10 / 03 / 2016$ & Rainy \\
P9AF & 0.5 & 14 & $11 / 03 / 2016$ & Rainy \\
P16BB & 0.5 & 14 & $05 / 04 / 2016$ & Dry \\
P14BA & 0.5 & 14 & $15 / 04 / 2016$ & Dry \\
P38AA & 0.5 & 14 & $28 / 04 / 2016$ & Dry \\
\hline
\end{tabular}

\section{Execution energy of the piles}

Silva (2011) [2] and Ferrari de Campos (2018) [3] showed that for CFAs executed within recommended and controlled technical conditions, the accumulated torque and, mainly, the work performed during the excavation of a pile can be a useful tool to analyse its bearing capacity.

Observing a single pile, it can be stated that the total energy dissipated or the total work performed during the excavation is the sum of: i) the work performed by the forces applied to the helicoid (auger); ii) the work performed by the pull down force; and iii) the initial In short, potential energy of the system in relation to the final excavation quota (Eq. 1, Silva, 2011) [2]. These work components are as follows:

$$
W_{R}=\int_{0}^{Z b} m h c \cdot g \cdot d Z+\int_{0}^{Z b} F_{d i} \cdot d Z+\int_{0}^{m 2 \pi} F_{i} \cdot r \cdot d \theta
$$

where: $\mathrm{W}_{\mathrm{R}}=$ work done or energy needed to excavate a pile $[\mathrm{J}] ; Z_{\mathrm{b}}=$ length of the pile $[\mathrm{m}]$; mhc $=$ mass of the drilling system $[\mathrm{kg}] ; \mathrm{g}=$ gravity $\left[\mathrm{m} / \mathrm{s}^{2}\right] ; \mathrm{F}_{\mathrm{di}}=$ downward force applied to the helicoid $[\mathrm{N}] ; \mathrm{F}_{\mathrm{i}}=$ force applied to the helicoid $[\mathrm{N}] ; \mathrm{r}=$ radius of the propeller pile $[\mathrm{m}] ; \mathrm{m}=$ number of turns of the helicoid during drilling.

The resulting accumulated execution energy along depth of the six piles studied, obtained through monitoring and sensors installed in the drill, are shown in Table 2.

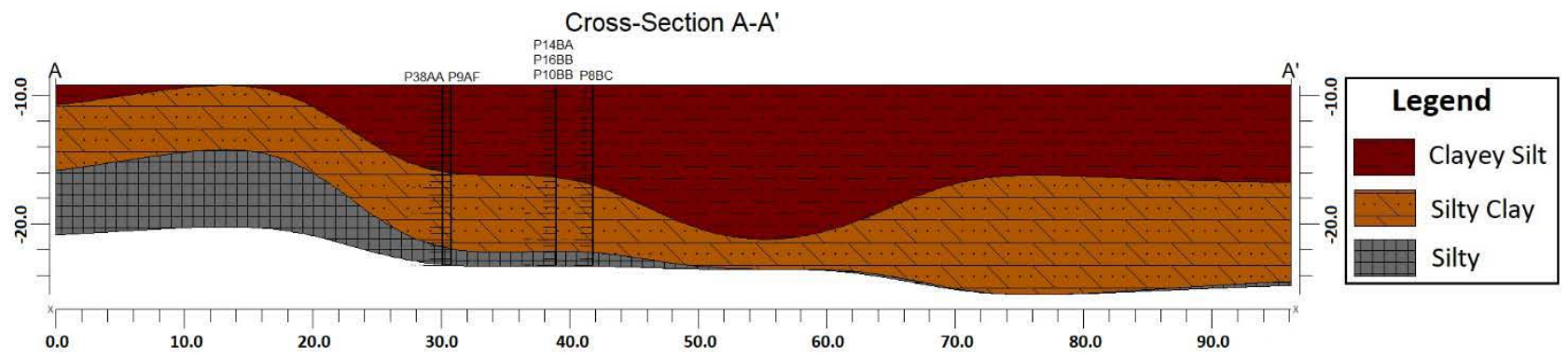

Fig. 1. Graph of the longitudinal section of the stratigraphic profile of the field and positioning of the analysed piles. 
Table 2. Accumulated execution energy of the pile along the depths.

\begin{tabular}{c|c|c|c|c|c|c}
\hline Depht (m) & P9AF (MJ) & P8BC (MJ) & P10BB (MJ) & P38AA (MJ) & P14BA (MJ) & P16BB (MJ) \\
\hline $0-1$ & 0.719 & 0.498 & 0.63 & 0.902 & 0.691 & 0.638 \\
$1-2$ & 2.752 & 2.387 & 2.277 & 3.187 & 2.687 & 2.49 \\
$2-3$ & 4.94 & 4.339 & 4.652 & 5.475 & 5.096 & 4.603 \\
$3-4$ & 7.363 & 6.523 & 6.903 & 7.829 & 6.966 & 6.974 \\
$4-5$ & 9.947 & 9.216 & 9.479 & 10.752 & 9.152 & 10.053 \\
$5-6$ & 13.05 & 11.102 & 12.021 & 13.624 & 11.136 & 13.256 \\
$6-7$ & 16.01 & 14.206 & 15.251 & 17.033 & 14.075 & 16.7 \\
$7-8$ & 18.61 & 17.264 & 18.431 & 20.123 & 16.312 & 20.164 \\
$8-9$ & 22.117 & 20.324 & 21.967 & 23.303 & 19.13 & 23.796 \\
$9-10$ & 25.124 & 24.757 & 25.057 & 25.994 & 21.811 & 27.945 \\
$10-11$ & 28.807 & 27.891 & 28.053 & 29.246 & 24.927 & 31.523 \\
$11-12$ & 32.164 & 31.023 & 31.607 & 34.204 & 27.876 & 35.177 \\
$12-13$ & 35.352 & 34.404 & 34.89 & 38.685 & 31.472 & 38.626 \\
$13-14$ & 38.675 & 37.972 & 39.241 & 49.739 & 36.121 & 41.902 \\
\hline
\end{tabular}

\section{Pluviometry Data}

Pluviometry data has been used to indirectly represent the seasonal state of the unsaturated soil profile. The idea behind this simplification is simple: rain is the most important factor which alters the saturation of the shallower strata of the soil profile. Therefore, instead of depending on the obtention of the soil-water characteristic curves of the materials involved and performing relatively complex soil-atmosphere modelling, a simple survey of the pluviometry data is considered instead.

Throughout the year, Brasília-DF is subjected to two very distinct seasons in terms of rainfall: a rainy period (from October to March) and a dry period (from April to September). Such changes, according to Camapum de Carvalho et al. (1995 and 2000) [4] [5], Mascarenhas (2004) [6] and Campos (2018) [7] affect the behaviour of the soil matrix, especially due to the change in water content along the soil profile.

The pluviometry data for the time window of 10 days prior to the date of execution of each pile was based on data collected by the National Institute of Meteorology (INMET) and is presented in Table 3 . Table 3 presents the data for Accumulated Precipitation (P), Accumulated evapotranspiration (E), Actual accumulated evapotranspiration (Er), Accumulated excess precipitation $(\mathrm{Pe}=\mathrm{P}-\mathrm{Er})$ and Accumulated precipitation deficit (Def $=E-E r)$. It is worth mentioning that all the data are in $\mathrm{mm}$.

Table 3. Antecedent atmospheric data (10 days) for each pile, $\mathrm{mm}$

\begin{tabular}{c|c|c|c|c|c}
\hline Pile & P & $\mathbf{E}$ & $\mathbf{E r}$ & Pe & Def \\
\hline P10BB & 80.4 & 30.19 & 27.84 & 52.56 & 2.35 \\
P8BC & 78.4 & 30.5 & 27.34 & 51.06 & 3.16 \\
P9AF & 79.8 & 32.5 & 29.34 & 50.46 & 3.16 \\
P16BB & 1 & 32.02 & 9.22 & 0 & 22.8 \\
P14BA & 0 & 39.49 & 16.48 & 0 & 23.01 \\
P38AA & 0.2 & 37.7 & 23.18 & 0 & 14.52 \\
\hline
\end{tabular}

To summarize all the data in Table 3, Eq. (2) (SETRALCPC, 1997) [8] was used to calculate the values of a Moisture Index (MI) proposed herein, defined as:

$$
M I=\frac{P e-0.6 D e f}{E r}
$$

Normally, annual rainfall events are considered in order to distinguish weather regimes. However, it is important to consider the precipitation events during relatively short antecedent periods which are close to the execution of the piles. The adoption of an antecedent period is motivated by the fact that there can be a change in behaviour in a dynamic manner during short periods of time. The resulting values of the humidity indexes of the 10 days analysed for each pile are shown in Table 4.

Table 4. Moisture ratios for each pile.

\begin{tabular}{c|c}
\hline Pile & Moisture Index (\%) \\
\hline P10BB & 183.73 \\
P8BC & 179.82 \\
P9AF & 165.52 \\
P16BB & -148.37 \\
P14BA & -83.77 \\
P38AA & -37.58 \\
\hline
\end{tabular}

\section{Analysis of results}

The performed analyses are based on the average energy values of each pile group, since the piles have similar characteristics. Fig. 2 shows the mean accumulated energy along the depth of the piles executed both during the rainy and the dry periods. Fig. 3 shows the same plot, now considering the meter-by-meter mean energy value. Finally, Fig. 4 shows the percentual difference between the accumulated and meter-by-meter energies for both raining regimes considered.

A clearer correlation is observed by considering the accumulated average energy. Considering Fig. 4, it is worth noticing that the differences occur more notably in shallow depths. This difference between the rainy and dry 
periods reaches approximately $21 \%$ in $1 \mathrm{~m}$ of depth, $13 \%$ in $2 \mathrm{~m}$ of depth, and $9 \%$ in $3 \mathrm{~m}$ of depth. For greater depths, the variation is more subtle, with values ranging between $1-5 \%$.

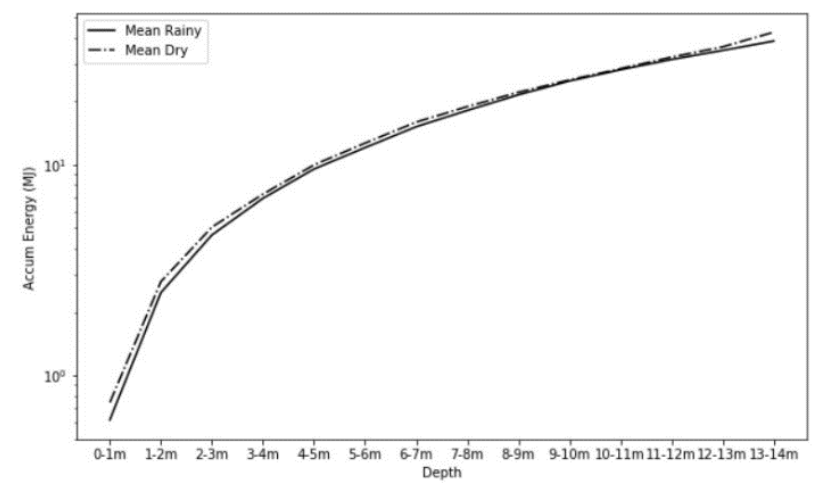

Fig. 2. Average accumulated energy along the depth in the different climatic periods.

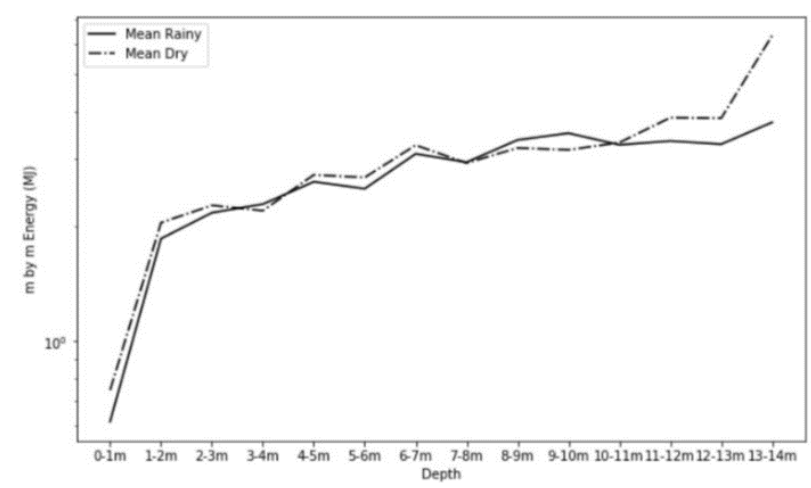

Fig. 3. Average energy meter by meter along the depth in different weather periods.

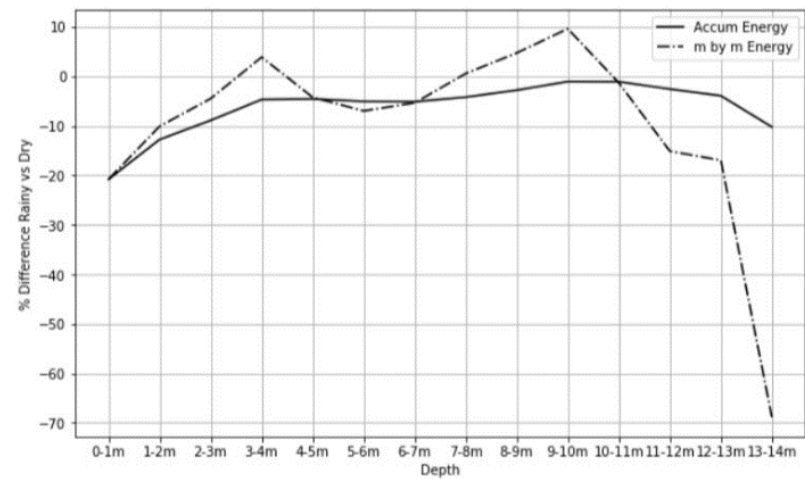

Fig. 4. Difference between average accumulated energy and meter-by-meter energy along the depth in different weather periods.

From a climatic point of view and according to Camapum de Carvalho et al. (1995) [4], in the region studied, the most significative changes in the degree of saturation occur predominantly in the initial 3 meters of the soil profile, where the variation of soil moisture reaches $35 \%$ throughout the year. For deeper strata, the soil moisture variations between the most humid and driest periods reach a maximum of $8 \%$. Studies by
Guimarães (2002) [9], Mota (2003) [10] and Lessa (2005) [11] also showed that the superficial layers of the soil in Brasília show greater wetting variations throughout the year. According to these authors, for the lower layers which are deeper than 3 meters, the soil is not significantly influenced by rainfall in a direct manner.

Also, Fig. 4 shows that for depths from $12 \mathrm{~m}$ to $14 \mathrm{~m}$, the difference between the meter-by-meter energies during rainy and dry seasons increases. The water table was found to be around $3 \mathrm{~m}$ deep, therefore this difference does not arise from a direct change of the water table level due to aquifer recharge issues. On the other hand, what may happen is that layers with different permeabilities may alter the recharging regime. This change in permeability along depth may subject the piles to two wetting fronts: one influenced by the atmosphere-soil interaction and another one influenced by the discharging/recharging of the subsurface water table. This second wetting front may change the drilling energy and, therefore, explain the behavior observed in in Fig. 4.

Another explanation can be suggested by analysing Table 2. Such table indicates that pile P38AA experiences a quick energy increase during the excavation of its last two meters of length. This may be caused by reaching a more resistant soil layer, while comparted to the other piles. This may affect the mean meter-by-meter energy and, therefore, cause the behaviour observed in Fig.4.

It is important to consider the region where the greatest variation of soil moisture occurred, because that is where matric suction fluctuates seasonally and, therefore, where the changes in the effect of the mechanical behaviour of unsaturated soils is more pronounced. When the soil-water characteristic curves of the soils are not available, relating the bearing capacity to the pluviometry data can be an interesting alternative.

The results of the present research suggest that pluviometry events may influence the execution energy of CFAs. Since there is a direct relation between this execution energy and the bearing capacity of CFAs, pluviometry events also influence the bearing capacity of such piles. Even though the observed direct influence is restricted to the top 3 meters of CFAs, shorter piles may have their lateral shaft resistance severely underestimated when purely saturated analyses are carried out. On the other hand, when collapsible soils are considered, the wetting/drying cycles of the shallower soil strata can lead to a separation between the pile shaft and the surrounding soils, resulting in potential overestimations of the bearing capacity of the pile if full contact was assumed. Properly considering the seasonal effects of weather conditons of the soil profile can lead to savings and greater safety in the design of piles.

\section{Conclusions}

Pluviometry events impact the execution of piles and, therefore, also impact their mechanical behaviour. Wetting/drying cycles and resulting stresses imposed to the soil mass while performing excavations also alter the mechanical response of piles when loaded. The morphology of the terrain affects not only the distribution 
of stresses but also the distribution of moisture inside the soil.

When considering pluviometry events, rains alter the soil moisture, which influences its degree of saturation and creates a saturation front which moves to the deepest layers of the soil profile. In the present paper, the such weather effects on the mechanical behaviour of CFAs has been studied.

In order to represent the change is soil moisture, a moisture index has been considered. This index is easily calculated from pluviometry data. On the other hand, in order to represent the bearing capacity of CFAs, their execution energies have been considered.

The results presented herein indicate that a more prominent effect of the moisture index is observed in the energy measurements along the first three meters close to the ground surface. Even though the observed influence is restricted to the top 3 meters of CFAs, shorter piles may have their lateral shaft resistance severely underestimated when purely saturated analyses are carried out. On the other hand, when collapsible soils are considered, the wetting/drying cycles of the top 3 meters can lead to the separation of the pile shaft and the surrounding soils, which would overestimate the bearing capacity of the pile when full contact is assumed.

Considering the results obtained, other case histories may be further analysed as the wetting/drying cycles are observed in every-day situations. The analysis approach presented here can be used for a better evaluation of the interactions between the construction site, the pluviometry events and the real bearing capacity of the subsoil.

\section{Acknowledgements}

The authors thank the University of Brasilia and CNPq for supporting this research.

\section{References}

1. J. Reinert. (2011). Study of the behavior of the deep foundations of industrial work in the coast of Rio de Janeiro using a probabilistic approach. Master's Dissertation, Federal University of Paraná, Curitiba. $182 \mathrm{p}$.

2. C. M. Silva. (2011). Energy and Reliability Applied to Continuous Helix Type Stakes. PhD Thesis, Department of Civil and Environmental Engineering, University of Brasilia, Brasília, 303p.

3. D. J. Ferrari de Campos. (2018). Energy of continuous flight auger piles execution as a tool to evaluate the competence of the field. Master's Dissertation, Department of Civil and Environmental Engineering, University of Brasilia, Brasilia, 126p.

4. J. Camapum de Carvalho., A. C. Mello., P. M. Santos Neto., C. M. Silva. (1995). Considerations on bearing tests on piles in collapsible soils with flooding. Meeting on unsaturated soils, Porto Alegre, 2: 159172.
5. J. Camapum de Carvalho \& S. Leroueil. (2000). Characteristic Curve Normalization Model. 32nd Annual Paving Meeting, Brasília, 1:96-106.

6. M. M. A. Mascarenha., J. Camapum de Carvalho., R. C. Guimarães. (2004). Use of pluviometric data in the evaluation of the load capacity of excavated piles. $5 \mathrm{th}$ Brazilian Symposium on Unsaturated Soils, São Carlos- SP, 5: 363-367.

7. D. J. F. Campos., L. C. S. M. Ozelim., J. C. Carvalho. (2018). Analysis of the influence of the operator on the reliability of the spatialization of survey results in a real case of work. XIX Braz. Congress of $S$. Mechanics and G. Engineering, Bahia, 19: 1-8.

8. Setra - LCPC (1997). Drainage Des Chaussées Et Des Plates-Formes Routteres. Guite Technique, 2: 23.

9. R. C. Guimarães. (2002). Analysis of the Properties and Behavior of a Lateritic Soil Profile Applied to the Study of the Performance of Excavated Piles. Master's Dissertation, Department of Civil and Environmental Engineering, University of Brasilia, Brasilia, 183p.

10. N. M. B. Mota. (2003). Advanced Field Trials on Unsaturated Porous Clay of Brasília: Interpretation and Application in Foundation Projects. PhD Thesis, Department of Civil and Environmental Engineering, University of Brasilia, Brasília, 335p.

11. M. A. S. Lessa. (2005). Influence of Pluviometric Indices on Tropical Soil Moisture as an Indicator of Suction Applied to Foundations. Master's Dissertation, Department of Civil and Environmental Engineering, University of Brasilia, Brasilia, 213 p. 